\title{
The Structural Relationship between Chinese Money Supply and Inflation Based on VAR Model
}

\author{
Shichang Shen, Xiaoyi Dong \\ School of Mathematics and Statistics, Qinghai Nationalities University, Xining, China \\ Email: 13909785766@163.com
}

How to cite this paper: Shen, S.C. and Dong, X.Y. (2019) The Structural Relationship between Chinese Money Supply and Inflation Based on VAR Model. $A p$ plied Mathematics, 10, 578-587. https://doi.org/10.4236/am.2019.107041

Received: July 3, 2019

Accepted: July 20, 2019

Published: July 23, 2019

Copyright ( 2019 by author(s) and Scientific Research Publishing Inc. This work is licensed under the Creative Commons Attribution International License (CC BY 4.0).

http://creativecommons.org/licenses/by/4.0/

\section{(c) (i) Open Access}

\begin{abstract}
With the development of economy, more and more attention is paid to the relationship between money supply and inflation in the economic field. This paper chooses consumer price index $(C P I)$ as an important index to measure the level of inflation, by choosing between January 2008 and March 2019 money in circulation $M 0$, narrow measure $M 1$, broad measure $M 2$, consumer price index $C P I$ monthly data as sample, building a vector autoregressive (VAR) model and using econometric methods of impulse response function and variance decomposition, and finally characterizes money in circulation $M 0$, narrow measure $M 1$, broad measure $M 2$ and the relationship between consumer price index $C P I$ and different sizes of the impact of inflation in the money supply relationship.
\end{abstract}

\section{Keywords}

Money Supply, The VAR Model, Inflation

\section{Introduction}

With the continuous development of China's economy, indicators such as gross national product, consumer price index and money supply have been important indicators to judge the state of macroeconomic development. Consumer price index $(c p i)[1]$ is an indicator to measure and judge deflation and inflation. And the control of money circulation has become particularly important, through the control of money circulation will directly affect inflation, affect the development of the whole economy. The influence of money supply on inflation is higher than that of fiscal deficit on inflation. The relationship between fiscal stimulus plan, money supply, public expectation and inflation, and finally the money 
supply is the most important factor affecting inflation mainly in [2] [3]. There is a close relationship between money supply and inflation. There is no inflation in their short term, but we should also guard against the pressure brought by stagflation. Yang Zihui et al. [4] studied the directed acyclic graph and found that the fiscal deficit had a certain impact on inflation but was not the most important one. Somethings can be inspected in [4] [5]. And the money supply has a strong asymmetric influence on CPI and does not depend on the state of the economy. Inflation is closely related to China's monetary policy [6] and asset inflation. This paper is based on the VAR model to show that the impact of different money supply on inflation is different.

\section{Materials and Methods}

\subsection{The VAR Model}

Vector autoregression (VAR) [7] is to establish a model based on the statistical properties of data. The VAR model constructs the model by taking each endogenous variable in the system as the lagged value function of all endogenous variables in the system, thus extending the univariate autoregressive model to the "vector" autoregressive model composed of multivariate time series variables.

In 1980, C. A. Sims introduced VAR model into economics, promoting the wide application of dynamic analysis of economic system. The mathematical expression of VAR $(\mathrm{P})$ model is:

$$
y_{t}=\Phi_{1} y_{t-1}+\cdots+\Phi_{p} y_{t-p}+H x_{t}+\varepsilon_{t}, t=1,2, \cdots, T
$$

$y_{t}$ is the column vector of endogenous variables in $k$ dimension, $x_{t}$ is the column vector of exogenous variables in $d$ dimension, $p$ is the lag order, and $T$ is the number of samples. $k \times k$ dimensional matrix $\Phi_{1}, \cdots, \Phi_{p}$ and $k \times d$ dimensional matrix $H$ are coefficient matrices to be estimated. $\varepsilon_{t}$ is a $k$ dimensional disturbance column vector, which can be correlated with each other synchronously, but not with its own lag value and not with the variables on the right-hand side of the equation.

\subsection{Granger Causality Test}

Proposed by Granger (1969) [7], another important application of VAR model is to analyze the causal relationship between economic time series variables. Granger solved the problem of whether $x$ caused $y$, mainly looking at the extent to which the present $y$ could be explained by the past $x$, and whether the addition of the lag value of $x$ improved the explanation degree. If $x$ is helpful in y prediction, or if the correlation coefficient between $x$ and $y$ is statistically significant, it can be said that " $y$ is caused by $x$ Granger".

Consider the mean square error (MSE) of the march period prediction:

$$
\operatorname{MSE}=\frac{1}{s} \sum_{i=1}^{s}\left(\hat{y}_{t+i}-y_{t+i}\right)^{2}
$$

This can be expressed as follows: if the mean square error obtained by pre- 
dicting $y_{t+s}$ based on $\left(y_{t}, y_{t-1}, \cdots\right)$ for all $s>0$ is the same as the mean square error obtained by $y_{t+s}$ based on both $\left(y_{t}, y_{t-1}, \cdots\right)$ and $\left(x_{t}, x_{t-1}, \cdots\right)$, then $y$ is not caused by $x$ Granger.

\subsection{Impulse Response Function}

Vector autoregression model (VAR) [8] is a non-theoretical model, so it is not necessary to analyze the mutual influence between its variables when it is analyzed, but the impact on the explained variable when it is impacted by an error term. Therefore, for the VAR model, it is difficult to explain the economic value of a single parameter estimate. In addition to prediction, an important aspect of its application is the dynamic characteristics of the system, that is, the response of an endogenous variable to residual shock (response). The impulse response function can be used to describe the impact of the random error on the current and future values of endogenous variables.

First $i$ endogenous variable of an impact not only directly affect the first i variable, and pass through the dynamic structure of the VAR model to other endogenous variables, impulse response function attempts to depict the influence of trajectory, shows how an arbitrary variable disturbance affect all other variables through model, finally and feedback to the process itself.

\subsection{Variance Decomposition}

In 1980 [8], Sims proposed the variance decomposition method according to the expression of VAR $(\infty)$, and provided the influencing relationship between variables in the VAR model:

$$
\begin{gathered}
y_{i t}=\sum_{j=1}^{k}\left(\theta_{i j}^{(0)} \varepsilon_{j t}+\theta_{i j}^{(1)} \varepsilon_{j t-1}+\theta_{i j}^{(2)} \varepsilon_{j t-2}+\theta_{i j}^{(3)} \varepsilon_{j t-3}+\cdots\right), i=1,2, \cdots, k ; t=1,2, \cdots, T \\
\operatorname{Var}\left(y_{i}\right)=\sum_{j=1}^{k}\left\{\sum_{q=0}^{\infty}\left(\theta_{i j}^{(q)}\right)^{2} \sigma_{j j}\right\}, i=1,2, \cdots, k
\end{gathered}
$$

We know that the contents of the brackets are the sum of the influences of the $j$ disturbance term $\varepsilon_{j}$ from the infinite past to the present time point on $y_{i}$.

In this paper, the consumer price index (CPI) cover 8 types of goods and services consumed nationwide, and the calculation formula of CPI is

$$
C P I=\sum_{i=1}^{\mathrm{n}} C P I_{i} \times \text { Weight }_{i}
$$

\section{Empirical Analysis}

\subsection{Data Preprocessing}

Data are derived from Wind database. Figures 1-4 are the sequential trend charts of $C P I, M 0, M 1$ and $M 2$ from January 2008 to March 2019. As the observed trend charts are not stable, the stationarity of unit root test series is further adopted. 
CPI

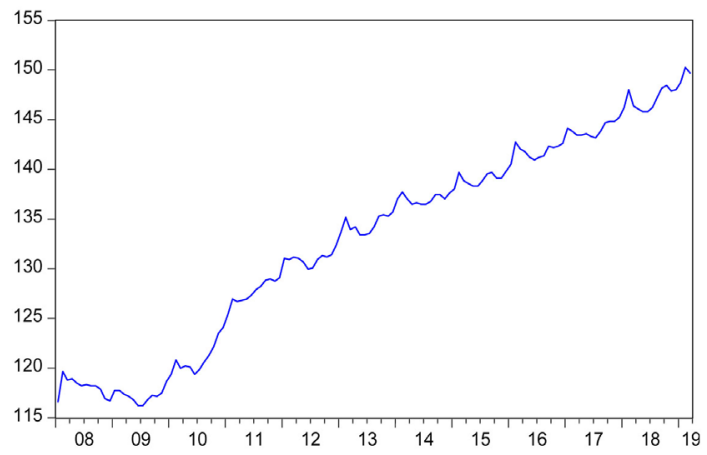

Figure 1. CPI trend chart.

MO

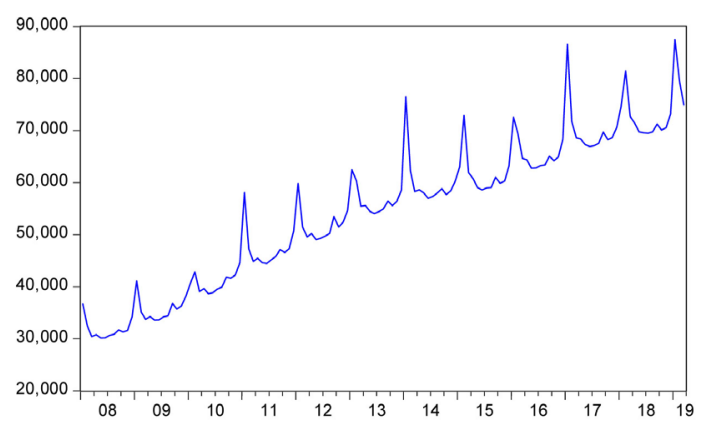

Figure 2. $M 0$ trend chart.

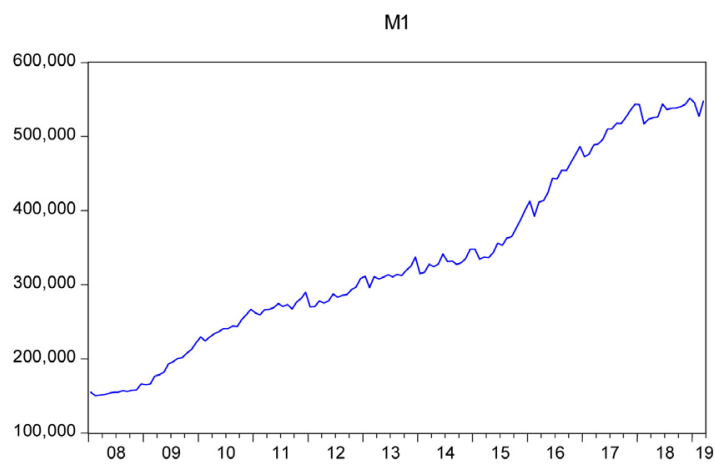

Figure 3. $M 1$ trend chart.

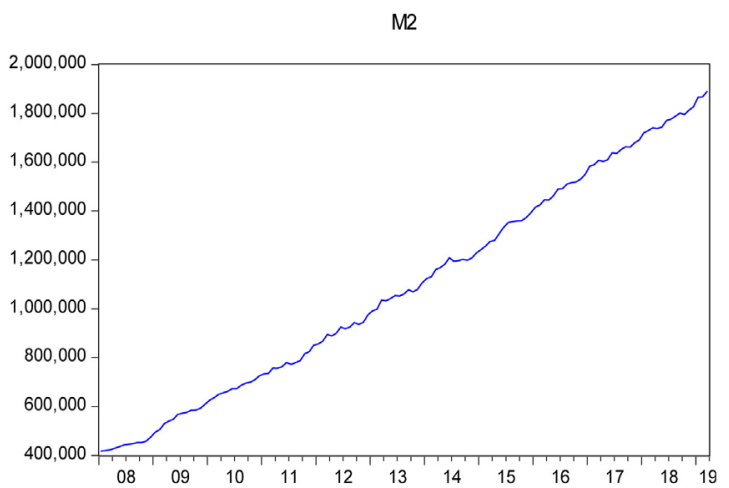

Figure 4. $M 2$ trend chart. 


\subsection{Stationarity Test}

In this paper, $\mathrm{ADF}$ unit root test was adopted to test the stationarity of the original sequence. The test results are shown in Table 1. By observing Table 1, CPI, $M 0, M 1$ and $M 2$ sequences failed the stationarity test.

Therefore, the first-order difference is carried out for the above sequences, and then the unit root test is carried out for the new sequences. The obtained results are shown in Table 2, and the new sequences after the first-order difference have been stabilized.

\subsection{Order Determination and Stability Test of the Model}

As can be seen from Table 3, the likelihood ratio (LR) is an indicator reflecting authenticity, which is a compound indicator reflecting both sensitivity and specificity. The final prediction error statistic (FPE) is a tool that provides prediction accuracy and high imitation, as well as a more general prediction checking capability. $D C P I, D M 0, D M 1$ and $D M 2$ are first-order integral sequences, so they can be judged according to the results of LR test statistics, final prediction error (FPE), AIC information criterion, SC information criterion and HQ information criterion, and there are enough lag terms and enough degrees of freedom at the same time. According to the results in Table 3, the optimal order of the VAR model is finally selected as order 2. By using EViews7.2 to establish the VAR (2) model, the vector autoregression expression about $C P I$ can be obtained as follows:

$$
\begin{aligned}
D C P I= & 6.4339 e-05 * D M 0(-1)+3.4488 e-05 * D M 0(-2) \\
& +0.1177 * D C P I(-1)+0.080 * D C P I(-2) \\
& +4.9877 e-05 * D M 1(-1)+1.9733 e-05 * D M 1(-2) \\
& -3.8129 e-07 * D M 2(-1)-3.6004 e-06 * D M 2(-2)-0.0062
\end{aligned}
$$

Table 1. ADF test results of $C P I, M 0, M 1$ and $M 2$ sequences.

\begin{tabular}{ccccccc}
\hline Variable & $\begin{array}{c}\text { ADF } \\
\text { test } \\
\text { value }\end{array}$ & $\begin{array}{c}\text { The critical } \\
\text { value at } \\
\text { the } 1 \% \text { level }\end{array}$ & $\begin{array}{c}\text { The critical } \\
\text { value at } \\
\text { the } 5 \% \text { level }\end{array}$ & $\begin{array}{c}\text { The critical } \\
\text { value at the } \\
10 \% \text { level }\end{array}$ & P values & Conclusion \\
\hline CPI & -320194 & -3.479656 & -2.883073 & -2.578331 & 0.9177 & Non-stationary \\
M0 & -2.488793 & -3.484653 & -2.885249 & -2.579491 & 0.1207 & Non-stationary \\
M1 & 0.225702 & $-3,480038$ & -2.883239 & -2.578402 & 0.9733 & Non-stationary \\
M2 & 2.070928 & -3.484653 & -2.885249 & -2.579491 & 0.9999 & Non-stationary \\
\hline
\end{tabular}

Table 2. ADF test results of $D C P I, D M 0, D M 1$ and $D M 2$ sequences.

\begin{tabular}{ccccccc}
\hline Variable & $\begin{array}{c}\text { ADF } \\
\text { test } \\
\text { value }\end{array}$ & $\begin{array}{c}\text { The critical } \\
\text { value at } \\
\text { the } 1 \% \text { level }\end{array}$ & $\begin{array}{c}\text { The critical } \\
\text { value at } \\
\text { the } 5 \% \text { level }\end{array}$ & $\begin{array}{c}\text { The critical } \\
\text { value at } \\
\text { the } 10 \% \text { level }\end{array}$ & P values & Conclusion \\
\hline CPI & -11.21752 & -3.480038 & -2.883239 & -2.578420 & 0.0000 & Non-stationary \\
M0 & -9.797663 & -3.484653 & -2.885249 & -2.579491 & 0.0000 & Non-stationary \\
M1 & -13.92312 & -3.480038 & -2.578420 & -2.578420 & 0.0000 & Non-stationary \\
M2 & -3.258272 & -3.484653 & -2.885249 & -2.579491 & 0.0191 & Non-stationary \\
\hline
\end{tabular}


Table 3. Delay order judgment results.

\begin{tabular}{ccccccc}
\hline & LogL & LR & FPE & AIC & SC & HQ \\
\hline 0 & -4152.109 & NA & $2.62 \mathrm{e}+22$ & 62.97134 & 63.05870 & 63.00684 \\
1 & -4076.024 & 146.4052 & $1.05 \mathrm{e}+22$ & 62.06097 & $62.49776^{*}$ & 62.23846 \\
2 & -4048.308 & $51.65193^{\star}$ & $8.83 \mathrm{e}+21^{\star}$ & $61.88346^{\star}$ & 62.66968 & $62.20294^{\star}$ \\
\hline
\end{tabular}

Note: ${ }^{\star}$ represents the optimal lag order of the corresponding criterion; LR represents likelihood ratio statistic; FPE represents the final prediction error statistic; AIC represents the chi information criterion statistics; SC represents Schwartz statistic; HQ represents the hannan-quinn information statistic.

After the estimation of the model, the inverse roots of the AR characteristic polynomial of the model should be tested, and the AR root diagram and tables can be obtained, as shown in Figure 4 and Figure 5.

According to Figure 5 and Table 4, the inverse roots of AR characteristic roots are all within the unit circle, and the overall stability of the model indicates that the VAR model composed of these indicators is effective, that is, there is a stable relationship between the money supply index and the inflation index.

\subsection{Granger Causality Test}

Granger causality test can further determine the causal relationship between each variable. The Granger causality test is conducted below, and the test results are shown in Table 5.

According to the data in Table 5, at the significant level of $10 \%$, there is a causal relationship between $C P I$ and $M 0, M 1$ and $M 2$, but it is not mutual. Instead, there is a one-way granger causal relationship, and the change of money supply is the cause of inflation.

\subsection{Impulse Response Function}

According to the impulse response diagram in Figure 6 and Figure 7, when $M 0$ increases, the $C P I$ changes very little, indicating that $M 0$ has a lag effect on $C P I$. In the 6th, 7th and 8th phases, $C P I$ has a negative effect on $M 0$, and reaches its maximum in the 9 th phase.

By observing the impulse response diagram in Figure 8, it can be concluded that the maximum value reached in the second phase produced a positive boost, and the negative effect was generated in the fifth phase, and the amplitude fluctuation decreased and tended to be near the 0 value in the end.

By observing the impulse response diagram in Figure 9, it can be concluded that in the first period, $M 2$ had no effect on $C P I$, and the impulse response value was 0 . After that, there was a negative impact in the fourth period, and then the fluctuation was gradually reduced until the response value approached 0 .

Variance Decomposition

Figure 10 is the variance decomposition graph of $C P I$, which is used in the VAR model to analyze the contribution to the change of endogenous variables. In this paper, the contribution of $M 0, M 1$ and $M 2$ to $C P I$ is adopted in anova. In 
Inverse Roots of AR Characteristic Polynomial

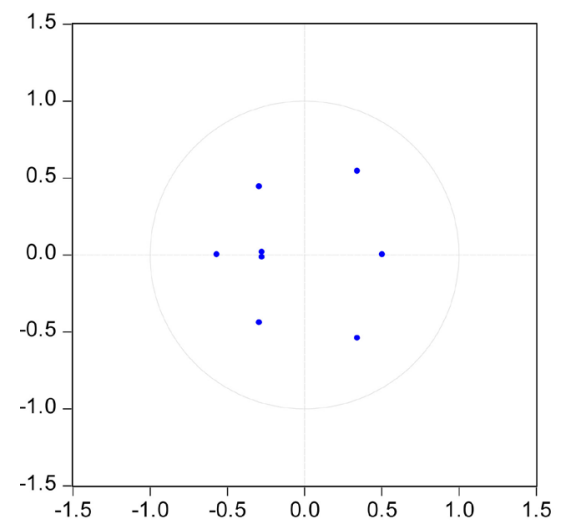

Figure 5. AR root diagram of VAR (2) model.

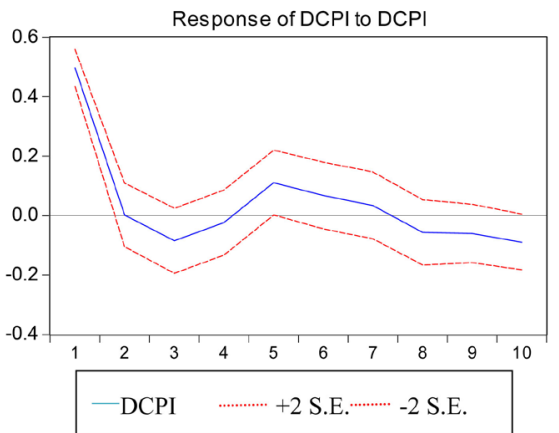

Figure 6. Impulse response of DCPI to DCPI.

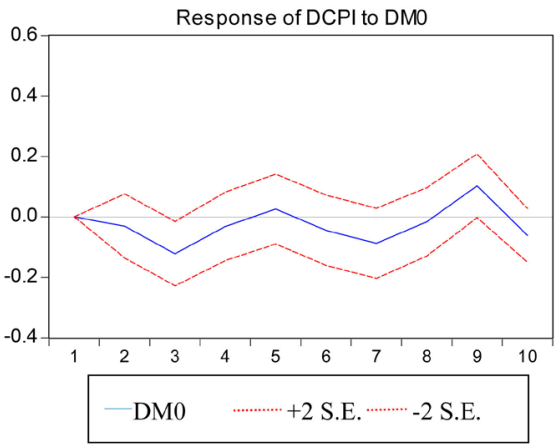

Figure 7. Pulse response of DCPI to DM0.

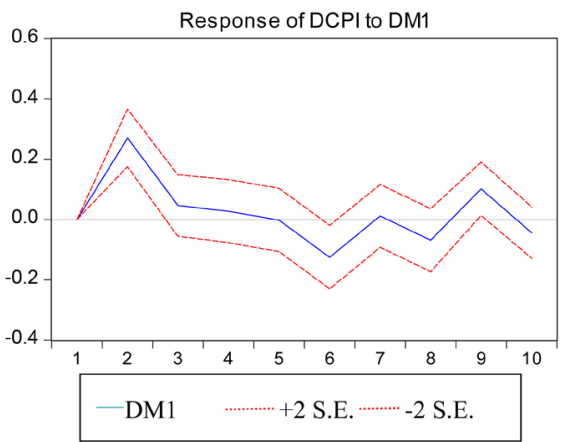

Figure 8. DCPI impulse response to DM1. 


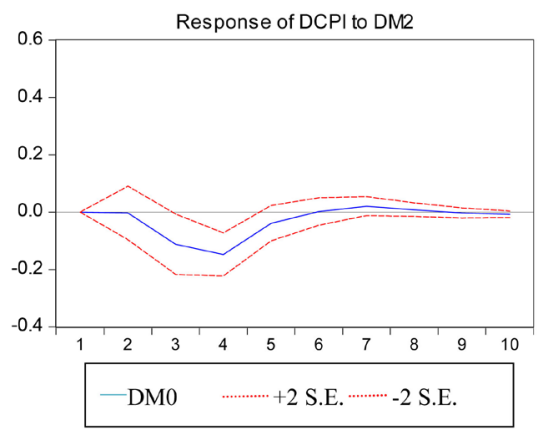

Figure 9. Impulse response of DCPI to DM2.

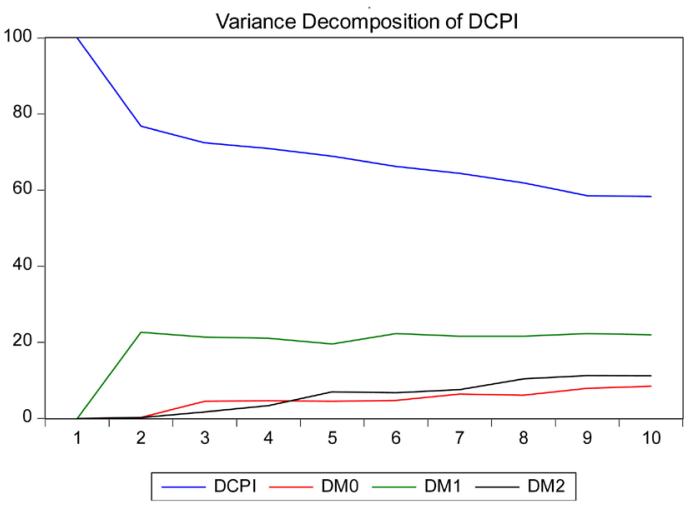

Figure 10. Variance decomposition.

Table 4. AR root table of VAR model.

\begin{tabular}{cl}
\hline Root & Modulus \\
\hline $0.343647-0.543592 \mathrm{i}$ & 0.643106 \\
$0.343647+0.543592 \mathrm{i}$ & 0.643106 \\
-0.564894 & 0.564894 \\
$-0.290970-0.442758 \mathrm{i}$ & 0.529809 \\
$-0.290970+0.442758 \mathrm{i}$ & 0.529809 \\
0.505074 & 0.505074 \\
$-0.272000-0.017187 \mathrm{i}$ & 0.272543 \\
$-0.272000+0.017187 \mathrm{i}$ & 0.272543 \\
\hline
\end{tabular}

Table 5. Results of Granger causality test.

\begin{tabular}{cccc}
\hline The null hypothesis & The F value & Probability (P value) & Conclusion \\
\hline DCPI is not the granger cause of DM0 & 0.810061 & 0.6670 & Accept \\
DCPI is not the granger cause of DM0 & 17.99314 & 0.0001 & Refuse \\
DCPI is not the granger cause of DM0 & 0.029371 & 0.9854 & Accept \\
DCPI is not the granger cause of DM0 & 40.54574 & 0.0000 & Refuse \\
DCPI is not the granger cause of DM0 & 3.940281 & 0.1394 & Accept \\
DCPI is not the granger cause of DM0 & 0.394868 & 0.0008 & Refuse \\
\hline
\end{tabular}


the first period, $C P I$ was only affected by itself. With the passage of time, the contribution rate of $C P I$ itself is gradually decreasing and the contribution rate of money supply variance is steadily rising.

\section{Conclusions and Recommendations}

Through correlation analysis such as impulse response function and variance as impulse response function and variance decomposition, the following conclusions can be drawn.

It is observed that the cumulative effect values of the corresponding impulse response functions $M 0, M 1$ and $M 2$ are greater than 0 , and it can be concluded that the increase of $M 0, M 1$ and $M 2$ will increase $C P I$. From the variance decomposition, it can be concluded that contribution rate of different money supply to $C P I$ is different.

The impact of $C P I$ is a certain lag, and the lag index $M 1$ is the leading indicator. Therefore, from the perspective of money supply, we should pay more attention to the change of $M 1$ indicator, and then pay attention to the change of $M 2$ indicator.

However, there is a significant short-term relationship between China's inflation and money supply, and money supply has a significant impact on inflation. This relationship is very obvious in the short run. In the long run, the influence of money supply on inflation will gradually weaken and stabilize at a relative level, and the volatility will gradually stabilize.

Therefore, it can be concluded that there is no inflation in China's economy in a short time, but it does not mean that the economy will develop steadily in the future, and stagflation may occur. At the same time, the monetary policy also has some lag and limitations. Therefore, we should establish a preventive mechanism in advance, and constantly improve some fiscal policies, formulate relevant systems, laws and regulations, so as to avoid some adverse impacts brought by inflation.

\section{Fund}

This work is supported by the National Natural Science Foundation of China (No. 11561056) and Natural Science Foundation of Qinghai (No. 2016-ZJ-914).

\section{Conflicts of Interest}

The authors declare no conflicts of interest regarding the publication of this paper.

\section{References}

[1] Zhang, W. and Su, J. (2010) Empirical Analysis of Output and Inflation Effect of Chinese Money Supply. Economic Issues, No. 5, 72-75.

[2] Gao, Y. (2010) Fiscal Stimulus Plan, Money Supply, Public Expectation and Inflation. Research on Fiscal and Economic Issues, No. 3, 8-16. 
[3] Guo, S.H., Li, X.X. and Wu, W.L. (2016) Research on the Relationship between Money Supply and Inflation. Productivity Research, No. 8, 15-17.

[4] Yang, Z.H. Zhou, T.Y. and Huang, X.F. (2014) Whether China's Fiscal Deficit Has Inflation Effect-New Evidence from the Study of Directed Acyclic Graph. Financial Research, No. 12, 55-70.

[5] Liu, L. and Zhu, M.N. (2013) Monetary Supply, Broad Money Velocity and Price Level-An Empirical Study on Chinese Data Based on Nonlinear LSTVAR Model. International Finance Research, No. 10, 20-32.

[6] Wu, Z.W. and Ju, F. (2003) Deflation, Asset Inflation and Monetary Policy-On the Current Monetary Aggregate and Monetary Structure in China. Management World, No. 11, 7-18.

[7] Yi, D.H. (2008) Data Analysis and Application of Eviews. China Renmin University Press, Beijing.

[8] Gao, T.M. (2009) Econometric Analysis Methods and Modeling-E Views Applications and Examples. 2nd Edition, Tsinghua University Press, Beijing. 